\title{
COMMENTARY
}

\section{Analysis of information flows of passive mobility}

\author{
Giuseppe Andrea De Biase ${ }^{1^{*}} \quad$ Annamaria Ruberto $^{2}$
}

\begin{abstract}
The health mobility is a right of the citizens that they can turn to any structure, without territorial restrictions, to look for an answer to their needs. Often produces inappropriateness and increases costs without affecting the quality of care. The purpose of this work is to study in depth the phenomenon of passive hospital mobility of Calabrian citizens through detailed and comparative analysis relating to the years 2014 and 2015, and the analysis of inappropriateness.
\end{abstract}

Keywords: health mobility, inappropriateness health, information flows

\section{Introduction}

Interregional healthcare mobility is the phenomenon that involves many patients who benefit from health services at facilities that do not belong to their region of residence.

This phenomenon entails the need to compensate for the costs of assistance for those patients for whom the per-capita funding of the NHS has been attributed to a region other than that in which the service was performed.

Health mobility, and in particular hospital mobility, which represents the main share, is a complex phenomenon. There is first of all a mobility that we can call proximity for which the user chooses the garrison that is most convenient even if territorially does not correspond to that formally to him. Then there is a programming component for some highly complex performances that you choose to locate in a few defined devices to guarantee a sufficient number of services needed to maintain high levels of performance excellence.

There is also a component of randomness associated with the movements and temporary displacements of the population, whether long-term, for example for work or study, or for a short or very short period such as in the case of holidays or occasional trips. Finally, there is a component due to the lack of supply on its territory, both quantitative and qualitative deficiency. Users choose a

\footnotetext{
Received: April 15, 2019 Accepted: May 24, 2019 Published: May 28, 2019

* Correspondence to: Giuseppe Andrea De Biase, Health and Health Policy Protection Department, Calabria Region, Italy; Email: giuseppe.debiase@ regione.calabria.it

${ }^{1}$ Health and Health Policy Protection Department, Calabria Region, Italy

${ }^{2}$ Catanzaro Provincial Health Authority, Italy

Citation: De Biase GA and Ruberto A. Analysis of information flows of passive mobility. Adv Health Behav, 2019, 2(1): 66-68.

Copyright: () 2019 Giuseppe Andrea De Biase. This is an open access article distributed under the terms of the Creative Commons Attribution License, which permits unrestricted use, distribution, and reproduction in any medium, provided the original author and source are credited.
}

garrison that is also distant in the need to be promptly treated or in the hope of being treated better. ${ }^{[1]}$

\section{Materials and methods}

The analysis conducted used the SDO 2015 data base on extra-regional mobility and that relating to 2014 to make comparisons. The data base contains hospital admissions and day Hospital (Flow A) provided, in other regions, to residents of Calabria. The calculations are based on the definitive data, that is, following the phases of disputes and counter-arguments.

The economic values indicated in the analyzes derive from the Debit request made by the donor region; as regards the data on the inhabitants, reference is made to the ISTAT data relating to the year analyzed.

In the section on inappropriate hospitalization the indicators of potential inappropriateness were calculated according to some of the calculation criteria provided in the annexes of the TUC, in particular the maldefined DRGs: 424, 468, 476 and 477; hospitalizations for ordinary acute repeated with time interval 0-1 day; ordinary hospitalizations repeated in departments code 56 with a time interval of 0-7 days; all packages of 3 or more consecutive admissions (with a time interval of 0-1 day) with the use of the code 56 department and for which the possibility of further disputes is envisaged. ${ }^{[2]}$

In order to identify and distinguish from "true mobility", the "false mobility" generated by subjects who, although resident in Calabria, live in other regions and, consequently, receive health services outside their region of residence, the BDA (Assisted Data Bank). ${ }^{[3]}$

\section{Results}

The total number of hospitalizations carried out in extra-regional health facilities, in favor of Calabrian cit- 
izens, has decreased from 63,571 in 2014 to 61,627 in 2015 , with a reduction of around $3 \%$.

In parallel with the reduction in the number of admissions, there was also a reduction of approximately $2.2 \%$ in the corresponding amount required for these services.

Despite this reduction, the economic impact of the phenomenon of passive mobility appears to be significant, as can be deduced from the average per-inhabitant charge which, for the year under analysis, amounts to $€$ 105.45 .

Of the total number of hospitalizations, 43,370 (corresponding to $70.37 \%$ of the total) were carried out under the ordinary hospitalization regime for a corresponding Debit totaling $€ 190,858,654.56$ (incidence equal to $90.84 \%$ of the total), while 18,257 (29.63\% of the total number of admissions) under the Day Hospital admission system for a total of $€ 19,256,183.83$ (9.17\%). The total number of accesses in Day Hospital was equal to a total of 39.643 .

In order to assess the complexity of hospitalizations performed outside the region, the average weight of hospitalizations was calculated, which is equal to 1.099 and the average charge for hospitalization is equal to $€$ $3,406.41$.

The age group with the highest extra-regional mobility (around 10\% for men and 8.6\% for women) is between 60 and 65 years of age. The 70-75 age class and the 6570 age group follow. For women there is a greater use of mobility for the 35-40 age group.

Mobility was mainly directed to the following regions: Lombardy (21\% of total debit), Lazio (16\% - excluding Bambin Gesù and Acismom), Emilia Romagna (13\%), Sicily $(11 \%)$, Tuscany $(7,5 \%)$, Puglia $(6.6 \%)$ and Piedmont $(5.2 \%)$. They absorb over $75 \%$ of the total admissions.

Analyzing the aggregate consumption referring to the year 2012 of the subjects present in the BDA, where the relative services were provided, and the presence of a choice of a GP outside the region, it can be seen that almost a quarter of the subjects present in the BDA did not use, in the year 2012, of health services.

A first possible sorting of the subjects that fall under the "false mobility" can be done by selecting the subjects who have received health services only and exclusively outside the region or who have received services both inside and outside the region but who have made the choice of a Medicine Doctor General (GP) outside the region.

Proceeding in this way, it can be seen that $37 \%$ of the subjects who have benefited from services outside the region can be traced back to the phenomenon of false mobility.

Mobility was mainly directed to the following regions (in order of debit): Lombardy, Lazio (excluding Bambin Gesu and Acismom), Emilia Romagna, Sicily, Tuscany, Puglia and Piedmont. They absorb over $75 \%$ of the total admissions and about $80 \%$ of the total expenditure.

The DRGs that involve the absorption of a greater share of expenditure, at the level of the destination region, are: 1) the DRG 104 "Interventions on heart valves and other major cardiothoracic operations with cardiac catheterization" in the Lombardy region; 2) the DRG 544 "Replacement of major joints or replanting of lower limbs" in Emilia Romagna, Lombardy and Tuscany; 3) the DRG 410 "Replacement of major joints or replanting of lower limbs" in Lazio.

The DRGs that involve the absorption of a greater portion of Debit, at the hospitalization level, are: 1) the DRG 424 "Surgical interventions of any kind in patients with the main diagnosis of mental illness" at "MINERVA S.P.A. SANTA MARIA DELLA SALUTE" in Campania for an economic value of more than one million euros and 145 hospitalizations; 2) the DRG 104 "Interventions on heart valves and other major cardiothoracic operations with cardiac catheterization" at the "CASA DI CURA ANTHEA" in Puglia for a total economic value of almost one million euros and 40 hospitalizations; 3 ) the DRG 009 "Spinal cord diseases and traumatisms" at the "MONTECATONE REHABILITATION INST" in Emilia Romagna where 25 hospitalizations are registered for a total amount of approximately 850 thousand euros.

The ranking based on the share of potentially inappropriate admissions as indicated in the 2015 TUC on the total number of admissions made within each destination Region sees, in terms of the number of admissions, the ACISMOM (59.26\%), followed by ABRUZZO (51.34\%), UMBRIA (48.14\%), BOLZANO (47\%), BAMBIN GESU '(46.02\%), LIGURIA (45.8\%), SICILY $(43.5 \%)$, TUSCANY $(41.26 \%)$, CAMPANIA $(40.73 \%)$.

In the analysis of the "ill-defined" DRGs the presence of a bell structure was found in which 145 health services were performed relating to the "maldefined" DRG 424 (Surgical interventions of any kind in patients with the main diagnosis of mental illness).

It should also be noted that the incidence of this DRG on the total benefits paid by this structure to Calabrian patients is approximately $98 \%$ of the total services provided.

\section{Conclusions}

From the analyzes carried out we highlight some anomalies in the appropriateness of some performances performed in certain structures of some regions. These situations can be discussed in the bilateral agreements 
with the regions concerned, in order to reduce any opportunistic behavior. Furthermore, it will be advisable to monitor these criticalities in subsequent years so as to check whether they are permanent over time.

The WHO defines the socio-economic status as the most important determinant of health.

The Calabrian citizens are already disadvantaged from an economic point of view, passive mobility creates a territorial inequality of health services and serious logistical problems.

\section{References}

[1] Agenzia nazionale per i servizi sanitari regionali. La mobilità sanitaria. Quaderno di Monitor n. 9. Anno XI Numero 29, Roma, 2012.

[2] Accordo interregionale per la compensazione della mobilità sanitaria. Approvato dalla Commissione Salute del 9 Maggio, 2012.

[3] Cislaghi C, Morandi I, DiVirgilio E, et al. La mobilità ospedaliera. Monitor, 2009, 120-130. 